\title{
MELHORIA DE PROCESSO CORROSIVO NA CÂMARA DE VAPOR DA MÁQUINA DE LINGOTAMENTO \#1 DA ARCELORMITAL TUBARÃO*
}

\author{
Demetrius Da Rós Ruy ${ }^{1}$ \\ Paulo Sérgio Soares Santiago ${ }^{2}$ \\ Vinicius dos Reis Carvalho ${ }^{3}$
}

\begin{abstract}
Resumo
O lingotamento contínuo é uma das etapas mais importantes na produção de aço, sendo um método rápido e eficiente na fabricação de placas ou tarugos através de processos de resfriamento onde o aço líquido é moldado e solidificado. Contudo, têm sido historicamente observado problemas de processo corrosivo acentuado na câmara de exaustão e na estrutura das máquinas da ArcelorMittal Tubarão. Os mecanismos deste processo corrosivo em máquinas de lingotamento contínuo, em geral, são variados e diretamente relacionados às condições operacionais da máquina, conduzindo a elevados custos de manutenção, diminuição da vida útil das máquinas, causando insegurança e interferindo na qualidade do produto. Este trabalho objetiva descrever as causas principais deste processo corrosivo e mostrar o desenvolvimento de testes que foram conduzidos visando a minimização deste fenômeno na máquina de lingotamento de placas \#1 da ArcelorMittal Tubarão no ano de 2017.
\end{abstract}

Palavras-chave: Lingotamento contínuo; Corrosão; Câmara de vapor; Sistema de resfriamento.

\section{CORROSION PROCESS IMPROVEMENT AT SPRAY CHAMBER OF THE CONTINUOUS CASTING MACHINE \#1 IN ARCELORMITTAL TUBARÃO}

\section{Abstract}

The continuous casting is one of the most important steps in the production of steel, being a fast and efficient method in the manufacture of slabs or billets through processes of cooling systems where the liquid steel is molded and solidified. However, it has been historically observed problems of strong corrosive process on steam chamber and structure of machines of ArcelorMittal Tubarão. The mechanisms of this corrosive process in continuous casting machines, in general, are varied and directly related to the operating conditions of the machine, leading to high maintenance costs, decreasing service life of the caster, causing insecurity and interfering in the product quality. This work aims to describe the main causes of this corrosive process and showing the development of tests that were conducted in order to minimize this phenomenon in the slab caster \# 1 of ArcelorMittal Tubarão

Keywords: Continuous casting; Corrosion; Spray chamber; Cooling system.

1 Engenheiro Metalurgista/UFOP, Especialista de Processo de Produção de Aço e Placas, Unidade Técnica da Aciaria/IAT, ArcelorMittal Tubarão, Serra, ES, Brasil.

2 Engenheiro Químico, Gerente Senior de Marketing, Divisão Nalco Water, Ecolab Química Ltda., São Paulo, SP, Brasil.

3 Engenheiro Metalurgista e de Materiais, Gerente de Conta, Divisão Nalco Water, Ecolab Química Ltda., Vitória, ES, Brasil. 


\section{INTRODUÇÃO}

A planta de lingotamento contínuo da ArcelorMittal Tubarão iniciou operação em 1995, sendo que existem 3 máquinas em operação, como descrito na Tabela-1.

Tabela 1. Dados de projeto das máquinas de lingotamento

\begin{tabular}{cccc}
\hline MÁQUINA & MLC\#1 & MLC\#2 & MLC\#3 \\
\hline Tipo & Placas & Placas & Placas \\
\hline Partida & 1995 & 1998 & 2007 \\
\hline Veios & 2 & $2($ twin $)$ & 2 \\
\hline Capacidade de prod. $(\mathrm{M} \mathrm{t} / \mathrm{ano})$ & $2,1-2,3$ & $2,4-2,6$ & $2,8-3,0$ \\
\hline Velocidade de Ling. $(\mathrm{m} / \mathrm{min})$ & 1,7 & 1,7 & 1,7 \\
\hline
\end{tabular}

Todas as máquinas possuem sistema de resfriamento primário (sistema de resfriamento fechado dos moldes), secundário (sistema direto de resfriamento de sprays - vide Figura 1) e de máquina (indireto).

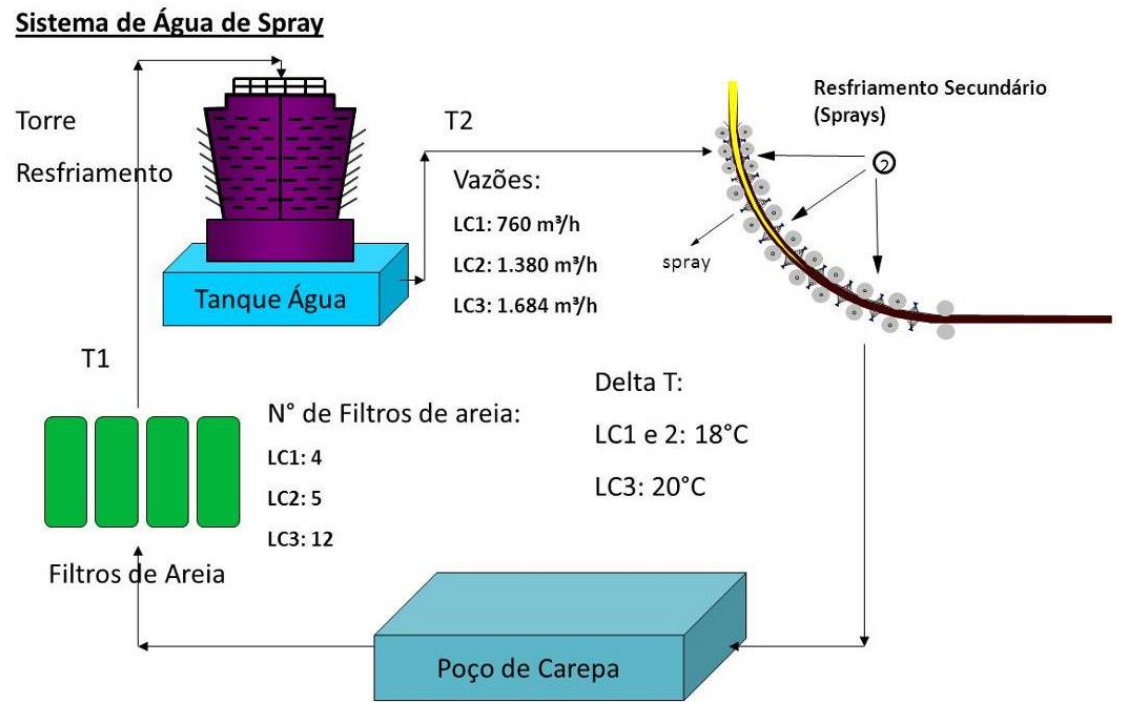

Figura 1. Sistema de resfriamento secundário.

Historicamente estas máquinas têm sido submetidas a processos corrosivos na câmara de vapor e na estrutura, sendo que em 2012 houve forte intervenção na MLC\#1 visando recuperação de sua estrutura conforme Figura 2.

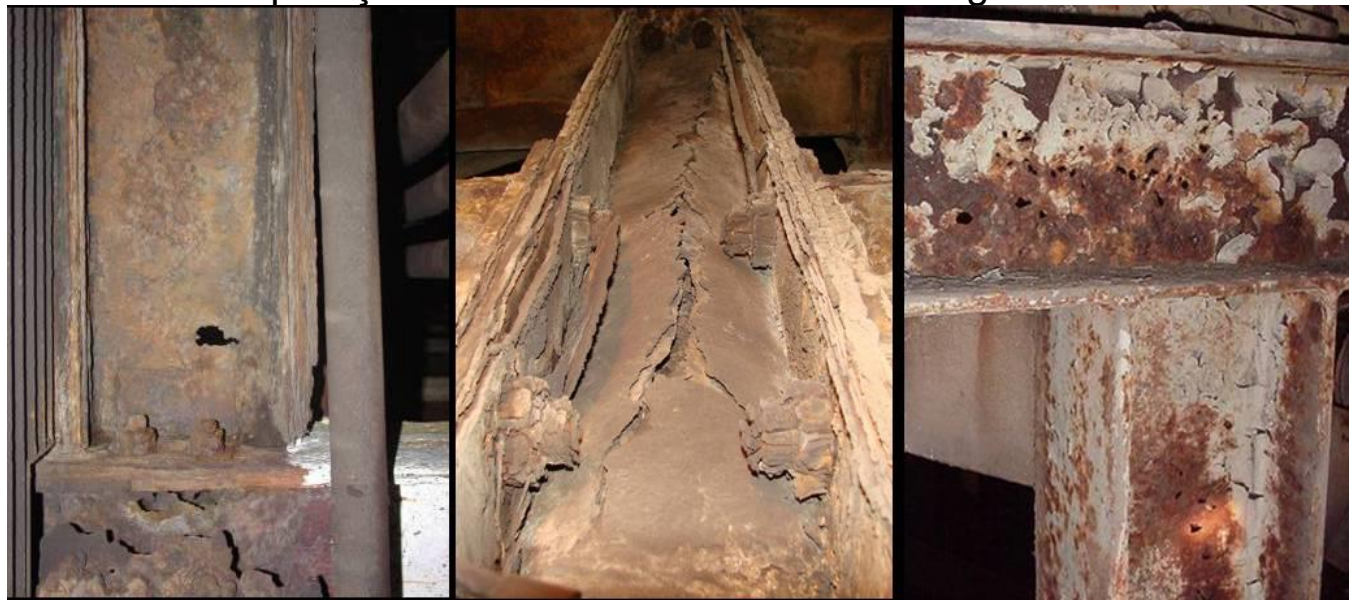

Figura 2. Partes da estrutura da MLC\#1 substituidas em 2012 
Tem sido realizado monitoramento contínuo das taxas de corrosão nas 3 máquinas, sendo que estes índices tem se mostrado elevado, na faixa de 12 - 60 MPY (milésimos de polegada/ano) entre 2014 e 2016.

\section{MATERIAIS E MÉTODOS}

O controle de corrosão em câmaras de vapor e na mesa de saída tem sido uma preocupação mundial em plantas de lingotamento contínuo. Os problemas associados com este processo corrosivo inclui: elevados custos de manutenção, diminuição da vida útil da máquina, preocupações com segurança e qualidade do produto. Algumas máquinas têm experimentado corrosão severa com velocidades de penetração extremamente rápidas;

É importante diferenciar o processo corrosivo nas partes internas da máquina (onde temos $100 \%$ de água) com este mesmo processo na estrutura da máquina onde a água evapora parcialmente. Em condições normais, a proteção contra a corrosão causada pela água oxigenada é conseguida com a aplicação de inibidores de corrosão usados no sistema de resfriamento. Contudo, quando ocorre evaporação desta água, isso é um fenômeno altamente problemático pois causa a concentração de ânions agressivos a concentrações muito mais elevadas que na água de resfriamento; também o oxigênio causa corrosão acentuada em temperaturas elevadas. Este fenômeno causa corrosão em aço carbono e baixas ligas

Certas máquinas podem experimentar severa corrosão por oxigênio em curtos períodos de tempo, enquanto outras podem ser minimamente afetadas. As condições que afetam a corrosão por oxigênio são: temperatura, projeto e operação do sistema, e exposição para outros agentes agressivos como ácidos (ânions agressivos). A presença de ácido, proveniente de elementos contidos nos pós fluxantes (F e C), acelera de forma alarmante a taxa de corrosão conforme exemplo da Figura 03.

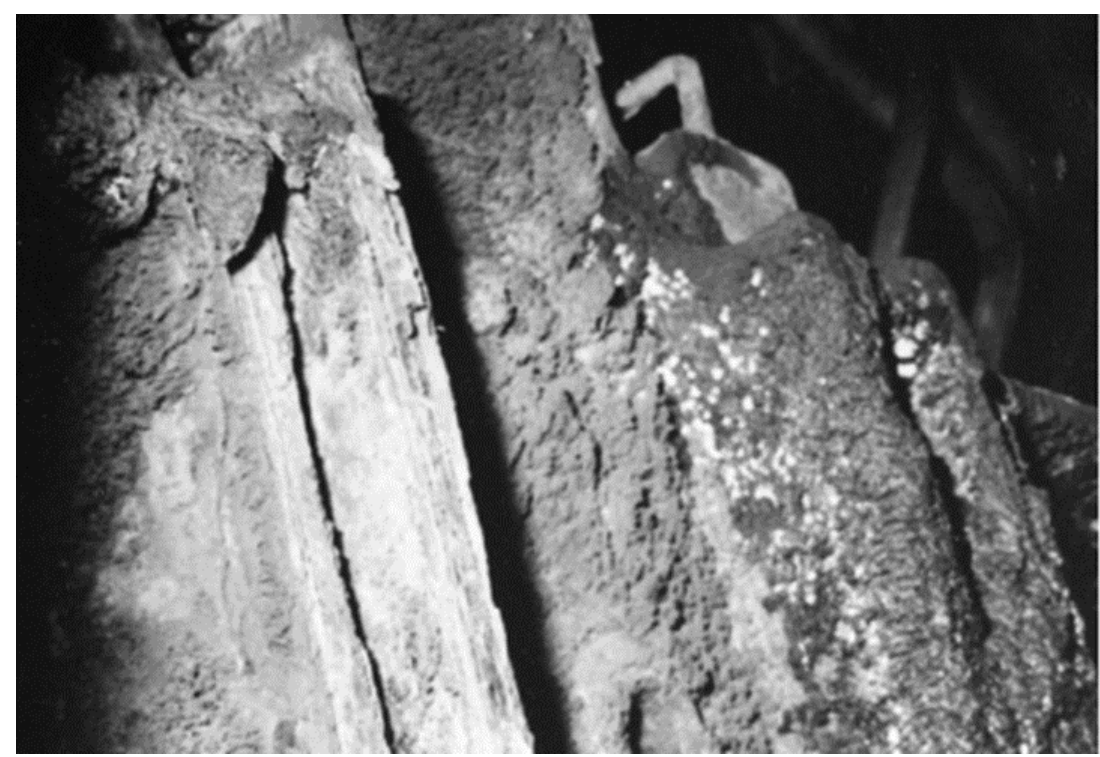

Figura 3. Exemplo genérico de severa corrosão por oxigênio em vigas estruturais na câmara de vapor; o aço-carbono é transformado em camadas de produtos de corrosão de óxido de ferro -8 anos de operação. 


\subsection{CORROSÃo ÁCIDA}

Máquinas que usam pós fluxantes podem sofrer corrosão ácida; este tipo de corrosão tem ocorrido em máquinas de muitos diferentes projetos e condições operacionais através do mundo. Os possíveis mecanismos e fatores que contribuem para a corrosão ácida são variados: é conhecido que durante o lingotamento, o fluoreto presente no pó fluxante $(7 \%, 10 \%$ ou mais) pode ser expurgado como componente volátil a níveis acima de 7\% como F; um dos componentes pode ser o tetrafluoreto de sílica [SiF4] conforme equações (1), (2) e (3);

$$
\begin{array}{r}
\mathrm{CaF}_{2}+2 \mathrm{H}_{2} \mathrm{O} \rightarrow \mathrm{Ca}(\mathrm{OH})_{2}+2 \mathrm{HF}(\mathrm{aq}) \\
\mathrm{CaF}_{2}+\mathrm{SiO}_{2}+\mathrm{H}_{2} \mathrm{O} \rightarrow \mathrm{CaSiO}_{3}+2 \mathrm{HF}(\mathrm{aq}) \\
\mathrm{SiF}_{4}+2 \mathrm{H}_{2} \mathrm{O} \rightarrow \mathrm{SiO}_{2}+4 \mathrm{HF}(\mathrm{aq})
\end{array}
$$

O fluoreto, na forma gasosa ou sólida, pode reagir com a água formando ácido fluorídrico; e o carbono pode se dissolver na água formando $\mathrm{CO}_{2}$. Em todos os casos, as espécies ácidas são extremamente solúveis em água enquanto que as espécies alcalinas são parcialmente solúveis. Condições que afetam a formação de ácido na água:

- Volume do Sistema - em sistemas com menor volume de água, tais como os que empregam air-mist no resfriamento secundário, pode ser particularmente suscetível a corrosão ácida;

- Alcalinidade da Água - a produção de ácido ocorre mais facilmente em sistemas que usam água de baixa alcalinidade;

- Temperaturas;

- Características do pó fluxante;

- Projeto do sistema;

- Condições Operacionais;

- Química da água - ácidos podem ser produzidos em algum grau pela concentração de outros agentes agressivos na água de resfriamento como cloretos, sulfatos e sulfetos;

- Concentrações ácidas ocorrem devido à evaporação da água em zonas de elevada temperatura;

- As condições variam de lugar para lugar dentro da câmara de vapor;

- O projeto e taxa de extração podem afetar a concentração de ácidos;

- Também, em áreas sob depósitos e entre fendas, íons agressivos como fluoretos e cloretos podem concentrar. Devido a esses mecanismos de concentração, pontos localizados podem ser muito mais agressivos que na água de resfriamento.

- A corrosão ácida pode causar severo desgaste de componentes; corrosão ácida tem sido preferencialmente encontrada em zonas próximas ao molde vez que o ácido é gerado nesta região;

- A mesa de saída não é exposta a ácidos da mesma forma que a câmara de vapor exceto sob condições pouco usuais. 


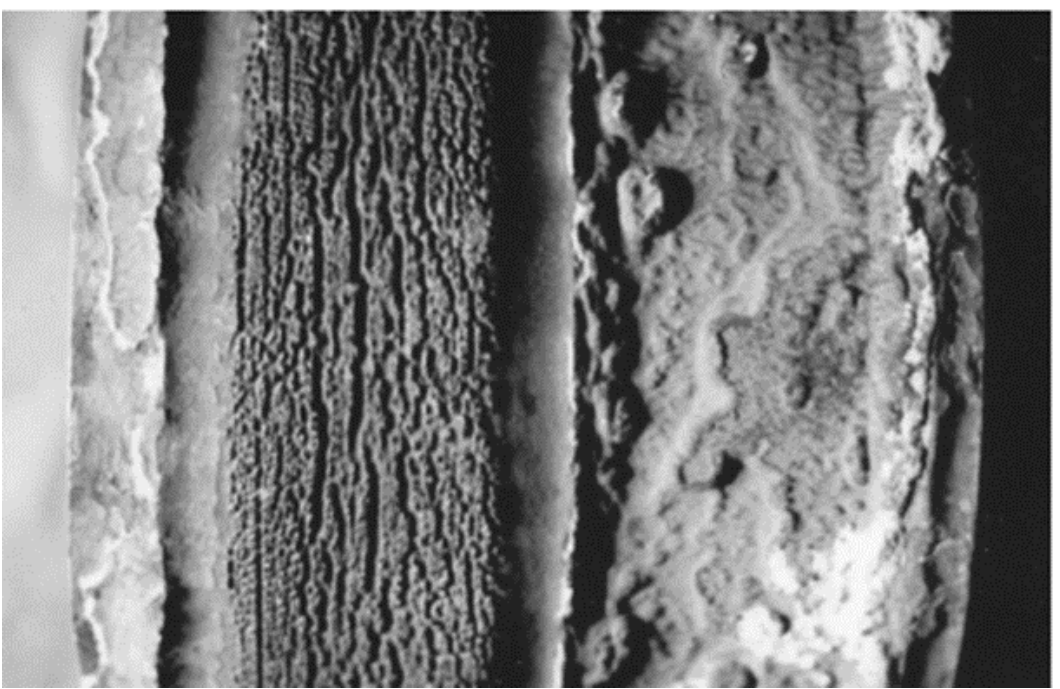

Figura 4. Exemplo de desgaste agressivo na superfície do foot-roll de uma siderúrgica: perda de 1/2 polegada de metal após duas semanas de operação. Amostras de depósitos indicou elevada presença de Fluoreto (ácido fluorídrico) ${ }^{1}$.

Um importante elemento na neutralização da corrosão ácida em água é a sua alcalinidade. Por definição, um teste de alcalinidade de uma substância está relacionado com a sua capacidade de neutralizar os ácidos. De forma geral, existe alcalinidade presente em água naturalmente por sais de bicarbonato ( $\left.\mathrm{NaHCO}_{3}\right)$ dissolvidos na água. De forma geral, águas naturais na Europa e Estados Unidos têm alcalinidade elevada: nos Estados Unidos, por exemplo, varia de 50 - 400 ppm, conforme dados do U.S. Environmental Protection Agency ${ }^{3}$ o que provê uma natural capacidade de neutralização da água.

A típica água nacional, no entando, tem características de baixa alcalinidade, sendo que a água de superfície usada na AMT tem entre $15-20$ ppm de alcalinidade total , contribuindo para uma alcanilidade final no sistema de spray da MLC\#1 entre 50 - 70 ppm.

Então, se a quantidade de alcalinidade presente na água de spray sob o molde for insuficiente para neutralizar todos os ácidos formados, o resultante $\mathrm{pH}$ da água pode ser inferior a 4,0. Assim, deve haver suficiente alcalinidade na água para manter este $\mathrm{pH}$ acima de 6,0 e um dispositivo de amostragem necessita ser instalado para permitir a mensuração do consumo de alcalinidade sob o segmento zero.

Este consumo de alcalinidade e a conseqüente redução de $\mathrm{pH}$ variam significantemente dependendo do pó fluxante sendo utilizado.

As principais alternativas consideradas para reduzir a corrosão ácida são:

a) Ajustar a alcalinidade total da água recirculante pela adição de bicarbonato de sódio (ou de carbonato de sódio) ou;

b) Injeção de soda cáustica na região do spray de água, acima do segmento zero ou;

c) Injeção de soda cáustica através de um sistema de spray dedicado abaixo do molde.

Assim, para minimizar a corrosão ácida nas áreas diretamente abaixo do molde (segmento zero), é essencial neutralizar todo o ácido formado e evitar quedas de $\mathrm{pH}$ abaixo de 4.0, com o uso de um agente alcalino. Esta neutralização pode ser conseguida localmente com o uso de soda, na região do segmento zero ou do molde, 
como indicado acima (alternativas b e c). Mas este uso da soda é de difícil controle, é localizado, e pode gerar muitas alterações de $\mathrm{pH}$ favorecendo a deposição de sais de ferro e de outros compostos (Zinco, Carbonato de cálcio) nos bicos sprays. Se aplicada na bacia da torre, como era feito na AMT, não gerava a alcalinidade mínima desejada na água de spray, não evitando a queda de $\mathrm{pH}$ abaixo do segmento zero (Figura 5):

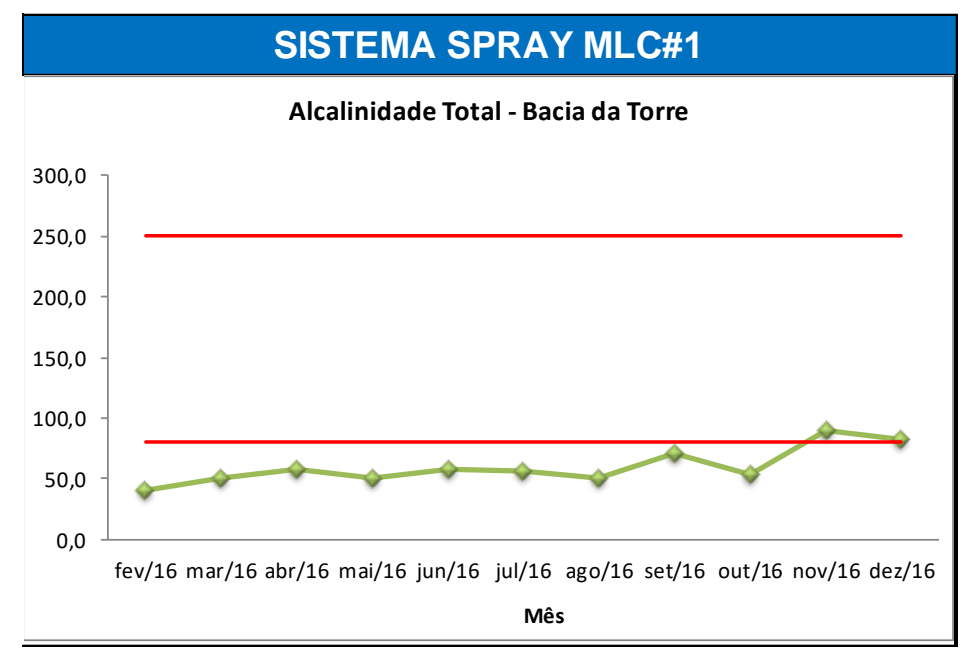

Figura 5. Controle de Alcalinidade da MLC\#1 antes dos testes.

Para conseguir uma adequada neutralização, uma quantidade suficiente de alcalinidade total é requerida e isso só pode ser conseguido com a aplicação de carbonato (ou bicarbonatos) de sódio apresentado na equação 04 :

$$
\mathrm{Na}_{2} \mathrm{CO}_{3}+\mathrm{HF}=>\mathrm{H}_{2} \mathrm{CO}_{3}+2 \mathrm{NaF}(4)
$$

Além de neutralizar a acidez livre, os carbonatos/bicarbonatos podem funcionar como um inibidor anódico se presente em concentração suficientemente alta, com dois mecanismos diferentes de inibição da corrosão: o íon bicarbonato pode servir como tampão do pH na zona anódica, contendo a velocidade de dissolução anódica; ou pode formar $\mathrm{FeCO}_{3}$ no ânodo numa solução de elevada alcalinidade. O carbonato de ferro (siderita) tem baixa solubilidade e pode formar uma barreira na zona anódica. ${ }^{4}$ Para determinar a alcalinidade total requerida é necessário uma intensiva amostragem sob o molde, abrangendo todos os tipos de pó fluxante usados em diferentes condições de lingotamento para determinar o $\mathrm{pH}$ nesta região. Recomenda-se a construção e instalação de um amostrador para coletar água do segmento zero sem expor operadores á condições de risco com a máquina em operação.

O ácido formado sob o molde será rapidamente neutralisado pela alcalinidade, contudo, se a alcalinidade for insuficiente na água de spray então o pH resultante pode cair a níveis muito baixos. A questão a ser respondida é: quanto de alcalinidade é requerida na água de suprimento do spray para prevenir $\mathrm{pH}$ abaixo de 6.0? Para responder a esta questão, foram desenvolvidos testes na MLC\#1 da ArcelorMittal Tubarão, os quais serão descritos no item 3 a seguir.

Alternativa de reduzir a corrosividade gerada pela corrosão ácida são através da aplicação de inibidores para a fase vapor, produtos a base de aminas neutralizantes e que devem ser aplicadas diretamente na câmara de vapor; idealmente esta aplicação deve ser ajustada através de um loop de controle com instalação de um pHmetro na água que sai do segmento zero. 
Aspectos importantes a serem considerados nesta alternativa:

- Os inibidores precisam cobrir as superfícies nuas e/ou as camadas superiores de oxidação ou não serão efetivos;

- Precisam ser corretamente dosados através da câmara de vapor. Pode ser difícil atingir zonas protegidas;

- Pode ocorrer perda significativa do inibidor através do sistema de ventilação;

- Segurança e odor;

- Potencial entupimento de bocais se dosado na linha de água do spray. Uma linha de dosagem separada deve ser considerada.

\subsection{CORROSÃO POR ESCAMAÇÃO}

Também chamada esfoliação, é caracterizada por múltiplas camadas de produtos de corrosão gerados na superfície da base do aço carbono, comumente encontrada na câmara de vapor, fora da região de contacto direto com a água, mas é particularmente notada na zona final da máquina. A perda de metal é severa sob os depósitos.

A Nalco realizou um levantamento em máquinas de lingotamento contínuo ao redor do mundo visando identificar as causas deste tipo de corrosão. Um número de fatores foi identificado, incluindo a geometria da câmara de vapor, taxa de extração do ar e posicionamento dos sprays, porém o principal fator acredita-se ser o teor de cloretos na água do sistema de spray. Este trabalho sugere que a corrosão por escamação não deve ser um problema quando a concentração de cloretos na água do spray estiver abaixo de 80 ppm.

Este cloreto é normalmente proveniente da água de reposição e da adição de produtos para tratamento da água. Uma significante contribuição vem da aplicação de biocidas oxidantes baseados em cloro gás ou hipoclorito.

O mecanismo de corrosão por escamação envolve a transferência de íons cloreto da água de spray para regiões não-úmidas da estrutura da máquina. O cloreto se deposita nas superfícies metálicas devido às condições úmida / seca nesta área. $\mathrm{O}$ cloreto então migra através dos produtos de corrosão de óxido de ferro e acelera a corrosão anódica do metal.
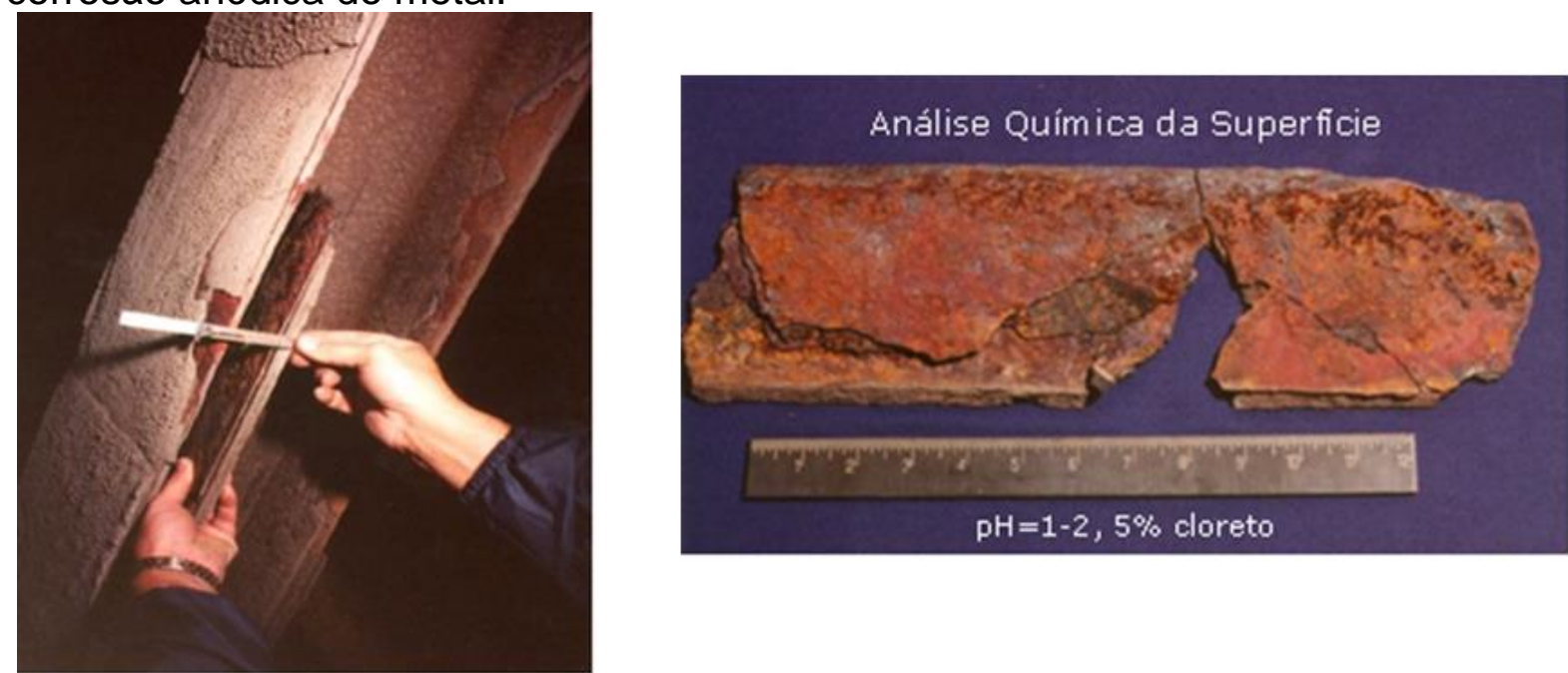

Figura 6. Exemplo de corrosão acentuada em uma viga estrutural causada por cloretos como consequência de aumento de cloração pelo aumento das contaminações de óleos e graxas.

Pesquisas feitas em cupons-teste instalados para avaliação de taxa de corrosão em vários segmentos de máquinas de lingotamento e analisados por difração por Raios$X$ mostraram que as concentrações de cloreto e de fluoreto variam através da 
máquina: na parte superior da máquina tanto o cloreto como o fluoreto estavam presentes; na parte final da máquina apenas íons cloretos foram encontrados. ${ }^{2}$

Tabela 2. Concentrações de cloreto $(\mathrm{Cl})$ e fluoreto $(\mathrm{F})$ por região da MLC.

\begin{tabular}{cc}
\hline SEGMENTO & COMENTÁRIO \\
\hline 0 & Predominantemente $\mathrm{F}$, algum $\mathrm{Cl}$ \\
3 & $\mathrm{~F} \mathrm{e} \mathrm{Cl}$ aproximadamente iguais \\
6 & $\mathrm{~F} \mathrm{e} \mathrm{Cl}$ aproximadamente iguais \\
9 & Apenas $\mathrm{Cl}$ \\
12 & Predominantemente $\mathrm{Cl}$, algum $\mathrm{F}$ \\
14 & Apenas $\mathrm{Cl}$ \\
\hline
\end{tabular}

Então é sumamente importante que se mantenha sob controle os teores de cloreto e fluoreto na água recirculante visando minimizar este processo corrosivo por escamação. As faixas recomendadas são: Cloretos < 100 ppm e fluoretos < 50 ppm. As análises na água de resfriamento de spray da MLC\#1 têm indicado os seguintes resultados (Figura 7 ):

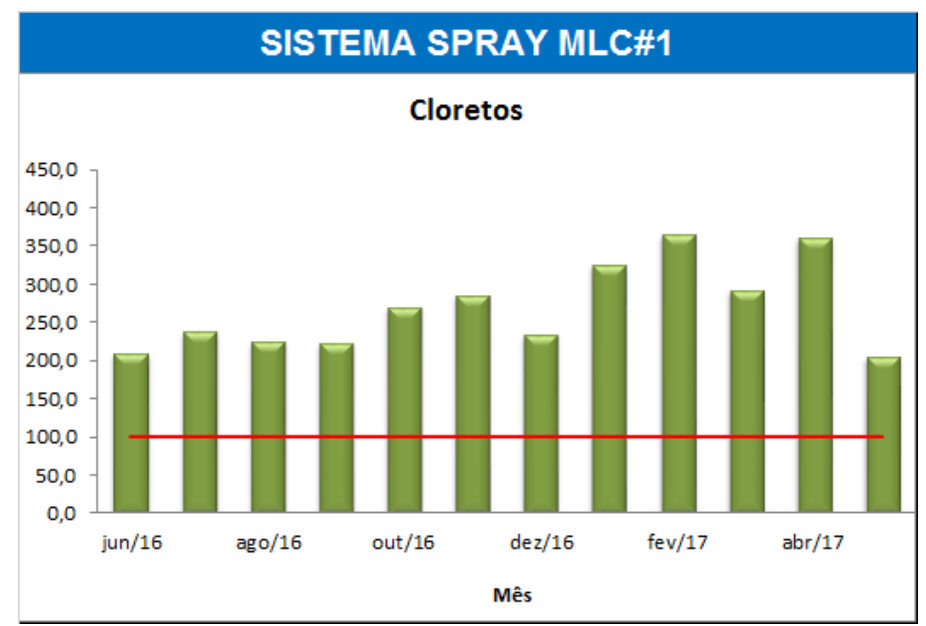

Figura 7. Resultados de cloretos na água de spray da MLC\#1

Estamos testando, então, a substituição do hipoclorito por outro biocida oxidante a base de bromo estabilizado, visando reduzir o teor de cloretos na água recirculante.

\section{RESULTADOS E DISCUSSÃO}

Decidiu-se, então, pela realização de testes na MLC\#1, com a sua realização em duas fases distintas, cada uma com duração de 90 dias:

Fase I: Aplicação de solução de carbonato de sódio $\left(\mathrm{Na}_{2} \mathrm{CO}_{3}\right)$ com concentração de 18 24\%, popularmente conhecido como barrilha, em substituição à soda caustica $(\mathrm{NaOH})$ para neutralização da corrosão ácida.

O cronograma de testes previu as seguintes etapas:

- Instalação de tanques para aplicação da solução de barrilha no poço de carepa da MLC\#1; 
- Realizado inspeção na máquina e registrados pontos específicos de monitoramento de processo corrosivo na estrutura da máquina e na câmara de vapor;

- Manutenção dos pontos de colocação de cupons de corrosão, em zonas específicas da máquina (Figura 8).

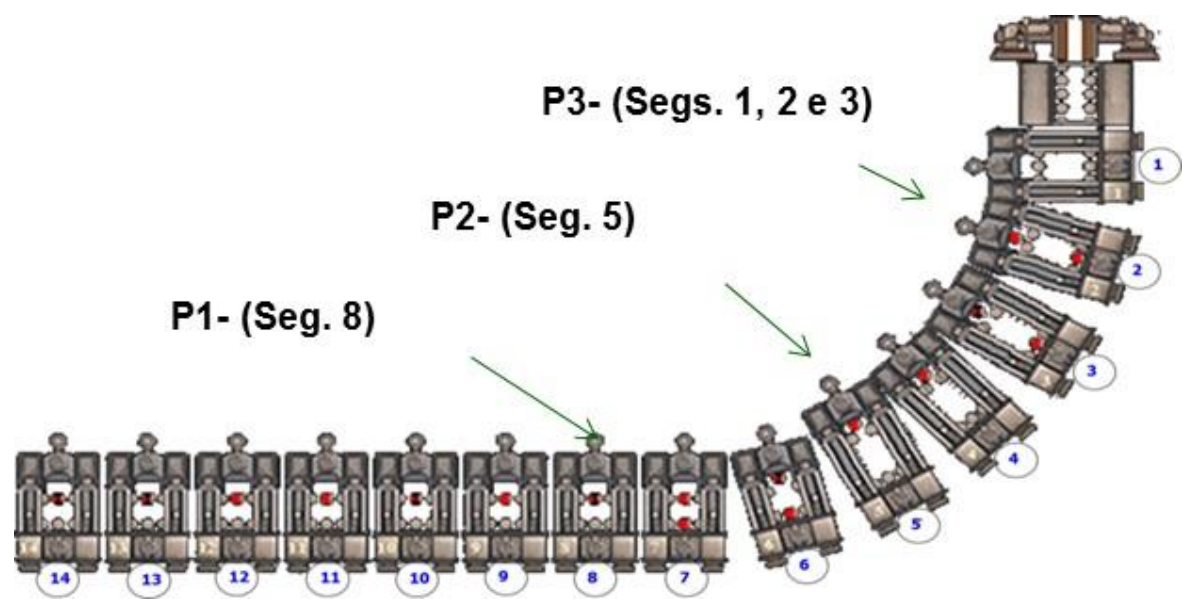

Figura 8. Pontos de colocação de cupons-teste na máquina

- Remover os cupons (com períodos de exposição entre 30 - 90 dias) para medição de taxa de corrosão e envio para análise metalográfica nos EUA visando identificar as causas dos processos corrosivos;

- Após a parada de 4/Jan/17 foi iniciada a aplicação de barrilha com as seguintes metas de controle:

a. Alcalinidade total: $120-250$ ppm na água de recirculação; frequência de medição: 2/dia na primeira semana; após isto: 1/dia;

b. $\mathrm{pH}>6$ na saída do segmento zero (amostrador local): 4/dia, na primeira semana; após: 2/dia;

c. Realização de análises bacteriológicas e observação crescimento biológico no Biobox;

- Resultados Obtidos na Fase I: 
$\Rightarrow$ Controles analíticos (Período de testes: 04/Jan/17 - 22/Mai/17) (Figura 9).
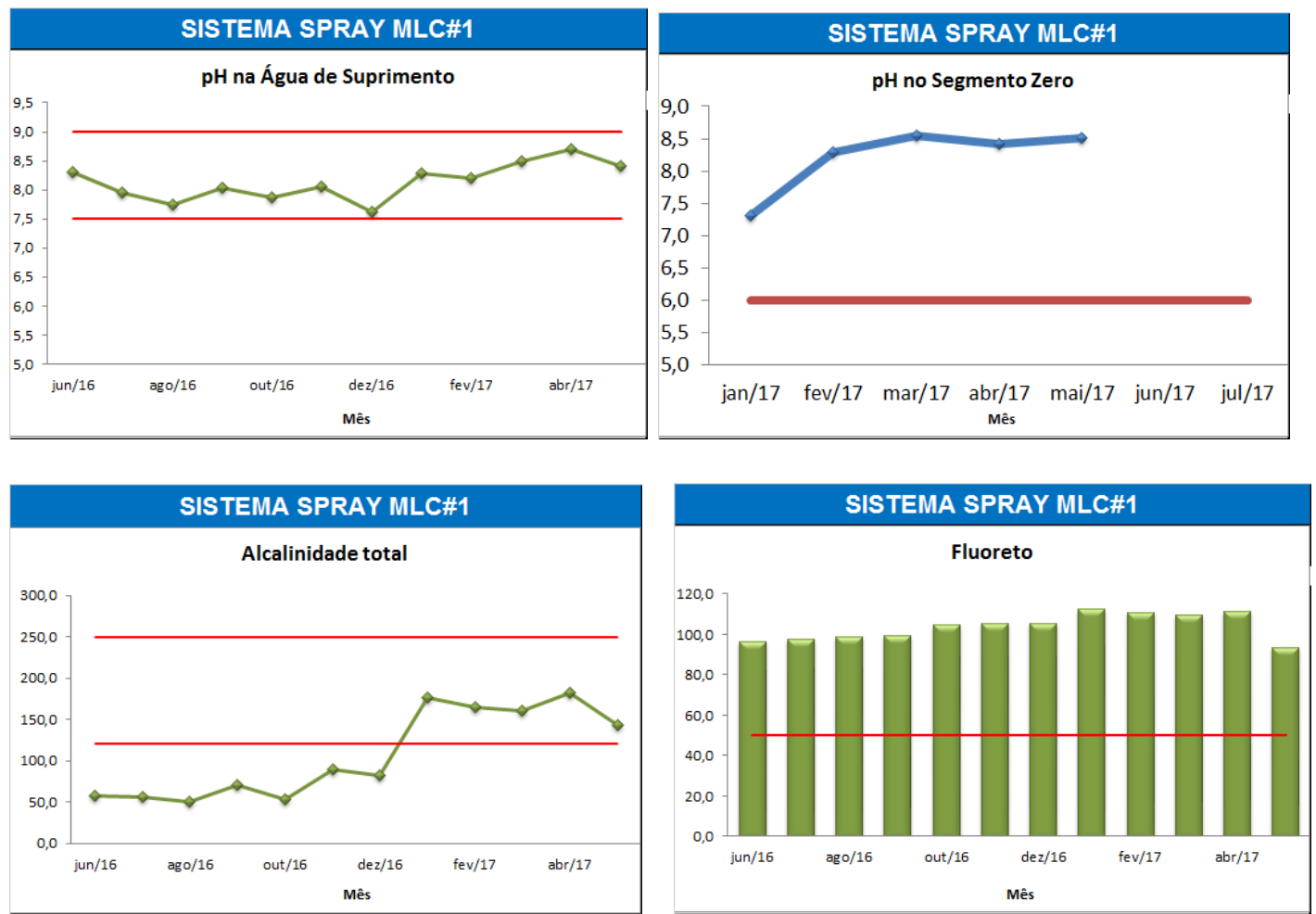

Figura 9. Gráficos de acompanhamento analítico do teste

Observa-se, então, que o aumento da alcalinida-M para a faixa de $120-200$ ppm foi adequado para manter o pH no segmento zero acima de 6,0 (antes, com a aplicação de soda, este parâmetro ficava enter 50-80 ppm). O teor de fluoreto manteve-se estável no período, indicando que não se alterou a contaminação com ácido fluorídrico.

$\Rightarrow$ Taxas de corrosão. Os resultados de corrosão encontrados no período antes e durante a aplicação da barrilha encontram-se na tabela 03 e em seguida a avaliação de aceitação dos resultados de corrosão (Figura 10).

Tabela 3. Taxas de Corrosão (mpy)

\begin{tabular}{lccc}
\hline Período & P1 & P2 & P3 \\
\hline 2016 - Média & 64 & 44 & 37 \\
\hline Antes do teste & 133 & Perdido* $^{*}$ & Perdido* $^{*}$ \\
\hline 42 dias após início & EUA 44,9 & EUA 18,3 & EUA 53 \\
\hline 56 dias após início & 87 & 26 & 18 \\
\hline 64 dias após início & 80 & 36 & 23 \\
\hline
\end{tabular}

\footnotetext{
*- Cupons foram perdidos ou extraviados.
} 
Avaliação de Tx. De Corrosão em

Câmara de Vapor

\begin{tabular}{|c|c|}
\hline $\begin{array}{c}\text { Taxa Corrosão } \\
\text { (MPY) }\end{array}$ & Avaliação \\
\hline$<10$ & Excelente \\
\hline $10<$ Corrosão $\leq 20$ & Boa \\
\hline $20<$ Corrosão $\leq 30$ & Aceitável \\
\hline $30<$ Corrosão $\leq 50$ & Pobre \\
\hline$>50$ & Muito pobre \\
\hline
\end{tabular}

Figura 10. Avaliação de aceitação dos resultados de corrosão

\section{$\Rightarrow$ CONTROLE MICROBIOLÓGICO:}

As contagens microbiológicas mantuveram-se sob controle $(<1.000 \mathrm{ufc} / \mathrm{ml})$ durante todo o período do teste.

\section{$\Rightarrow$ COMENTÁRIOS SOBRE A FASE I:}

- As taxas de corrosão na posição P1 (segmento 8) tem apresentado historicamente valores mais elevados e isso se manteve após a aplicação com barrilha, visto que a taxa de corrosão neste ponto sofre maior influência dos cloretos que tem se mantido elevados na água de resfriamento (250350 ppm); o resultado de 133 mpy antes do teste foi medido nos EUA, com maior precisão, e deve-se considerar o seu valor relativo e não necessariamente o absoluto; a taxa seguinte de corrosão, medida nos EUA, indicaram 44,9 mpy, indicando uma boa redução, mas com taxas ainda moderadamente elevada. As taxas dos demais cupons retirados tem indicado valores entre $80-87$ mpy, elevados demais.

- A análise metalográfica do cupom enviado aos EUA indicou corrosão por $\mathrm{O}_{2}$, agravada por elevada concentração de cloreto e ausência de evidência de corrosão por HF.

- As taxas no ponto P2 (segmento 5) apresentaram redução média de 39\% após a aplicação da barrilha; a análise metalográfica de cupom enviado aos EUA indica: "Chemical spot tests indicated the presence of material that was neutral in a distilled water solution and contained no significant amounts of chloride" indicando uma ação efetiva da barrilha aplicada. E "No significant evidence of hydrofluoric acid corrosion was found ..." 
- As taxas no ponto P3 (próximo ao segmento zero) têm apresentado forte redução em relação à média de taxas de corrosão em 2016 , indicando um bom efeito da aplicação da barrilha; de forma inesperada, apresentou taxa elevada no cupom enviado aos EUA (53 mpy), embora indique que "Chemical spot tests indicated the presence of material that was neutral in a distilled water solution and contained significant amounts of chloride. " $E$ "No significant evidence of hydrofluoric acid corrosion was found...", indicando o sucesso na aplicação da barrilha.

\section{CONCLUSÃo}

Os resultados de taxas de corrosão e as análises metalográficas confirmaram, assim, o sucesso da aplicação da barrilha visto que a corrosão ácida foi evidentemente minimizada gerando acentuada redução na região do segmento zero da máquina.

No entanto, a corrosão por cloretos continua acentuada, principalmente no cupom instalado no segmento 8 visto que não houve ação sobre a corrosão motivada por este parâmetro. Esta ação fará parte da Fase II do teste, em andamento, onde o biocida oxidante a base de cloro foi substituido por outro a base de bromo estabilizado.

Resultados iniciais já mostram acentuada redução do teor de cloretos, de 300 para < 100 ppm, o que pode gerar forte redução adicional nos processos corrosivos, mas esta fase II do teste está na fase de início e os resultados ainda precisam ser confirmados.

\section{REFERÊNCIAS}

1 J.J. Dillon. Continuous Casting Corrosion. Reprint R-654, Nalco an Ecolab Company. 2002.

2 Stephen A. Brell, Tim Jaques, Anthony J. Pask. Slab Caster Spray Chamber Corrosion. Association of Iron and Steel Engineers (AISE) Pittsburgh. 2003.

3 James M. Omernik, Glenn E. Griffith, Jeffrey T. Irish, and Colleen B. Johnson Environmental Research Laboratory U.S. Environmental Protection Agency Corvallis, Oregon 9733312 NSI, Technology Services Corp. Corvallis, Oregon 97333 - https://water.usgs.gov/owq/alkus.pdf

$4 \quad$ PAC 3 Technical Manual, Section.3.4.2., page 22, Nalco Water 